\title{
РАЗВИТИЕ ЧЕЛОВЕЧЕСКОГО ПОТЕНЦИАЛА, СОЦИАЛЬНАЯ ПОЛИТИКА И ЭЛЕКТРОННОЕ ГРАЖДАНСКОЕ УЧАСТИЕ В РОССИЙСКИХ РЕГИОНАХ
}

\begin{abstract}
Человеческий потенциал, социальная политика и электронное гражданское участие взаимообусловлены. С одной стороны, грамотное социальное инвестирование в человеческое развитие- важное условие появления спроса на механизмы участия со стороны граждан, что в свою очередь усиливает готовность органов власти к внедрению инноваций. С другой стороны, электронное участие само по себе является воплощением социального инвестирования, направленным на усиление «обратной связи» общества по вопросам реализации социально-экономической политики. В статье тестируется данная взаимосвязь применительно к российским регионам. За последние годы в России появилось большое количество площадок электронного участия. Однако исследователи часто отмечают их недостаточную эффективность, а также существенные диспропорции в их развитии на региональном уровне. С помощью авторской методики оценки нами были получены данные о представленности и функциональном развитии каналов электронного участия в субъектах РФ. Полученные показатели были использованы в количественном исследовании. Результаты корреляционного и регрессионного анализа свидетельствуют о значимости человеческого потенциала и социальной ориентированности
\end{abstract}

Юрий Андреевич Кабанов-ст. преподаватель, Департамент политологии и международных отношений, научный сотрудник, Центр сравнительных исследований власти и управления, Национальный исследовательский университет «Высшая школа экономики»; аналитик, Отдел мониторинговых исследований, Центр технологий электронного правительства, Институт дизайна и урбанистики, Национальный исследовательский университет ИТМО, Санкт-Петербург, Россия. Электронная почта: ykabanov@hse.ru

Андрей Владимирович Чугунов-к.полит.н., директор, Центр технологий электронного правительства, Институт дизайна и урбанистики, Национальный исследовательский университет ИТМО, Санкт-Петербург, Россия. Электронная почта: chugunov@itmo.ru 
бюджетов регионов для развития электронного участия по сравнению с другими потенциальными предикторами: развитием политических институтов, качеством государственного управления, а также расходами на ИКТ. Нельзя утверждать, что человеческое развитие с неизбежностью приводит к росту «спроса» на электронное участие со стороны граждан или «предложения» подобных механизмов со стороны органов власти. Однако наш анализ позволяет сделать вывод о важности социальной политики для его развития: помимо вложений в цифровую инфраструктуру, необходимо активное социальное инвестирование в человеческий потенциал. К возможным направлениям инвестиций здесь можно отнести выравнивание возможностей через повышение качества жизни незащищенных социальных групп, развитие социальных программ для активного населения, выравнивание региональных диспропорций, а также инвестирование в цифровые компетенции граждан и общественные инициативы.

Ключевые слова: человеческое развитие, социальное инвестирование, электронное участие, гражданское общество, регионы России

DOI: 10.17323/727-0634-2021-19-1-101-114

За последние несколько лет в России на разных уровнях власти появилось большое количество площадок электронного участия (ЭУ), под которым понимается «комплекс методов и инструментов, обеспечивающих электронное взаимодействие граждан и органов власти с целью учета мнения граждан в государственном и муниципальном управлении при принятии политических и управленческих решений» (Чугунов 2017:59). Однако эффективность ЭУ часто ставится под сомнение (Волошинская 2016; Ревякин 2018), а на уровне регионов фиксируются существенные диспропорции в его развитии (Kabanov, Sungurov 2016; Chugunov et al. 2016).

Выявление причин подобной ситуации невозможно без учета социально-политического контекста, в котором такие инновации развиваются. Особое место в объяснении успешности ЭУ занимает человеческий потенциал (или человеческое развитие), включающий уровень образования, продолжительность жизни и доход (Голяшев, Лобанов 2018: 156). В теории он не только способствует росту востребованности гражданского участия как института (Pirannejad et al. 2019), но и подталкивает власть к созданию новых форматов вовлечения граждан (Norris 2001; Lee et al. 2011; Krishnan et al. 2017; Tavares et al. 2020). В свою очередь, человеческое развитие напрямую связано с концепцией социального инвестирования, предполагающей активную социальную политику и трансформацию государства благосостояния за счет «повышения и поддержания "запасов" человеческого капитала на протяжении всей жизни» (Hemerijck 2018: 812).

Настоящее исследование представляет собой анализ влияния человеческого потенциала и социальных инвестиций на развитие ЭУ в регионах 
России. Используя авторскую методику оценки состояния ЭУ в субъектах РФ (Chugunov et al. 2020), мы делаем попытку эмпирически оценить значимость социальных факторов, влияющих на спрос и предложение ресурсов ЭУ (Pirannejad et al. 2019), а также определить возможные направления развития этих ресурсов за счет социального инвестирования. Предварительные данные исследования использованы в главе «Взаимовлияние электронного участия и человеческого потенциала в российских регионах» коллективной монографии (Чугунов, Филатова 2020:95-107).

\section{Электронное участие, человеческое развитие и социальное инвестирование}

Человеческий потенциал- важная тема исследований в области ЭУ. С одной стороны, новые технологии рассматриваются как необходимый стимул человеческого развития (Spirakis et al. 2010). С другой стороны, человеческое развитие часто выступает независимой переменной, формирующей спрос и предложение на ЭУ (Pirannejad et al. 2019). Как пишет Пиппа Норис, социальное развитие создает «большие стимулы для институтов общественного сектора к инвестициям в формы предоставления услуг и коммуникации через цифровые каналы» (Norris 2001: 105). Таким образом, через рост человеческого потенциала создается «общественное давление», подталкивающее власть к инновациям (Lee et al. 2011; Krishnan et al. 2017). Подчеркивается и позитивная роль отдельных компонентов человеческого потенциала (образования, дохода, качества жизни и др.) на политическую «эффективность» (efficacy) и активность граждан (Pirannejad et al. 2019).

Отсюда следует важность вложений государства не только в ИКТ, но и в социальную политику, способствующую человеческому развитию. Хотя инвестиции в сокращение «цифрового разрыва» по-прежнему актуальны, необходимы дополнительные усилия по преодолению обусловленного социально-экономическим неравенством «разрыва участия», ведущего к диспропорциональности общественных запросов, подаваемых через каналы ЭУ (Hargittai, Jennrich 2016). По мнению исследователей, более интенсивная поддержка уязвимых социальных групп позволяет преодолевать экономические и психологические барьеры на пути к их полноценному гражданскому участию (Marx, Nguyen 2018), а активная социальная политика, напрямую затрагивающая интересы граждан, повышает их интерес к институтам и практикам участия (Shore 2020).

Новый этап изучения этой проблематики связан с концепцией социального инвестирования (Hemerijck 2018). В отличие от традиционных моделей государства благосостояния, социальные инвестиции позволяют более эффективно добиваться инклюзии уязвимых групп, способствуя их более активной позиции на рынке труда и в общественно-политической 
жизни (Marx, Nguyen 2018:916). Кроме того, повышение гражданского участия через «консультации, коммуникацию и вовлечение на местном уровне» является важной формой реализации социального инвестирования (Jenson 2012: 39). ЭУ здесь дает дополнительные преимущества, поскольку ИКТ позволяют «напрямую вовлекать граждан в процесс разработки и управления социальными услугами» (Misuraca et al. 2017: 14).

ЭУ, человеческое развитие и социальное инвестирование (шире-peжим государственного благосостояния) находятся в состоянии взаимообусловленности: социальное инвестирование способствует развитию ЭУ, что в свою очередь помогает улучшать социальную политику государства через вовлечение граждан. Способствует ли человеческое развитие и более активная социальная политика появлению ЭУ в России? Хотя работ по региональному ЭУ в России достаточно много, в основном они ограничиваются изучением отдельных наиболее успешных и известных проектов (Kabanov, Chugunov 2017; Ревякин 2018). Немногочисленные попытки провести количественный кросс-региональный анализ наталкиваются на проблему доступности и полноты эмпирических данных (Kabanov, Sungurov 2016; Chugunov et al. 2016).

В попытке заполнить эту лакуну в данном исследовании мы тестируем значимость человеческого потенциала на уровне регионов России, концептуализируя эту связь через модель «общественного давления», где с ростом человеческого развития возникает спрос на новые инструменты участия в публичной политике (Norris 2001; Lee et al. 2011). Отсюда наша гипотеза, что чем выше уровень человеческого развития в регионе, тем выше в нем уровень развития ЭУ (H1). Вторая наша гипотеза связана с ролью активной социальной политики, в т. ч. социального инвестирования и социальной помощи (Marx, Nguyen 2018; Shore 2020). Мы предполагаем, что чем выше социальная ориентированность политики региона, тем выше в нем уровень развития ЭУ (H2).

Кросс-национальные исследования указывают и на значимость иных условий, например качества государственных институтов (Jho, Song 2015; Tavares et al. 2020). В российском контексте этот фактор приобретает особую значимость, поскольку модель «общественного давления» здесь очевидным образом сдерживается состоянием политических и бюрократических институтов (Gel'man, Starodubtsev 2016; Кынев 2017). Отсюда исходят гипотезы о том, что на развитие ЭУ будут положительно сказываться относительная открытость политических институтов (H3) и эффективность государственного управления в регионе $(H 4)$.

\section{Дизайн исследования}

Наша зависимая переменная-степень развития ЭУ- отражает наличие каналов электронной коммуникации региональных властей и граждан, а также 
качество их реализации. Для количественной оценки состояния ЭУ в субъектах РФ нами была разработана авторская методика (Chugunov et al. 2020). Полученные на основе этой методики данные для 85 субъектов РФ за 2019 г. используются в этой работе. Независимые переменные операционализируются с помощью рейтингов и данных статистики. Из-за отсутствия в ряде случаев актуальных данных мы используем имеющиеся показатели за 2016-2019 гг. Это ограничение необходимо учитывать при интерпретации результатов.

Основная независимая переменная нашего исследования- уровень человеческого развития в регионе, которую мы операционализируем через несколько показателей. Во-первых, это данные за 2016 г., представленные в Докладе о человеческом развитии в РФ Аналитического центра при Правительстве РФ. В анализе применяются как общий индекс (ИЧР), так и его компоненты: (1) душевой ВВП; (2) индекс дохода; (3) ожидаемая продолжительность жизни; (4) индекс долголетия; (5) грамотность; (6) доля учащихся в возрасте 7-24 лет и (7) индекс образования (Голяшев, Лобанов 2018). Во-вторых, мы используем рейтинг регионов по качеству жизни агентства «РИА Рейтинг» за 2019 г. Методология рейтинга отличается от принятой методики оценки человеческого потенциала и включает большее количество показателей, однако он также позволяет оценить уровень дохода, благополучия и образования населения (РИА Рейтинг 2020а).

Вторая независимая переменная - социальная ориентированность политики- измеряется нами через показатель доли социальных расходов на душу населения в 2019 г. (РИА Рейтинг 2020b). Данный индикатор нужен для оценки уровня государственного социального инвестирования (например, образование, здравоохранение, социальная помощь), хотя следует учитывать, что он включает расходы и на другие сферы (культура и спорт).

Третья независимая переменная - уровень развития политических институтов- операционализируется через данные Александра Кынева, рассчитанные на 1 января 2017 г. (Кынев 2017). Его методика включает оценку уровня политической конкуренции, независимости региональных депутатов, защиты прав парламентской оппозиции и состояние местного самоуправления. Это позволяет оценить условную степень «демократичности» и открытости региональных политических систем.

Для операционализации четвертой независимой переменной-качество государственного управления-мы используем данные Рейтинга эффективности управления в субъектах РФ в 2019 г. (Орлов, Туровский 2020), конкретно- данные по направлению «политико-управленческий блок», включающему эффективность работы губернатора и региональной бюрократии, а также взаимодействие региональных и федеральных властей.

Кроме того, в анализ включен ряд контрольный переменных. Вопервых, мы учитываем подушевые расходы региона на информатизацию через Рейтинг ИКТ-бюджетов регионов за 2019 г. (CNews Analytics 2019). Во-вторых, мы включаем бинарные переменные о принадлежности региона 
к тому или иному федеральному округу, чтобы проконтролировать макрорегиональные особенности.

\section{Результаты анализа}

Для проверки гипотез мы используем корреляционный анализ Пирсона и множественную линейную регрессию. Результаты корреляционного анализа (табл. 1) демонстрируют сильную положительную взаимосвязь развития электронного участия и человеческого потенциала, хотя не все компоненты ИЧР одинаково значимы. Кроме того, наблюдается столь же значимая связь между развитием ЭУ и социальной ориентированностью региональных бюджетов. При этом не обнаруживается такой же сильной и значимой связи с другими потенциальными предикторами: качеством политических институтов, государственного управления, а также расходами на информатизацию.

Таблицуа 1

Коэффициенты корреляции переменных с индексом развития ЭУ (источник: расчеты авторов)

\begin{tabular}{lc}
\hline \multicolumn{1}{c}{ Переменные } & Коэффициент корреляции \\
\hline Душевой ВВП & $.115(.295)$ \\
\hline Индекс дохода & $.430(.000)$ \\
\hline Ожидаемая продолжительность жизни & $.091(.410)$ \\
\hline Индекс долголетия & $.091(409)$ \\
\hline Грамотность & $.288(.007)$ \\
\hline Доля учащихся 7-24 лет & $.137(.212)$ \\
\hline Индекс образования & $.149(.173)$ \\
\hline Индекс человеческого развития & $.455(.000)$ \\
\hline Уровень развития политических институтов & $.173(.114)$ \\
\hline Качество государственного управления & $.232(.033)$ \\
\hline Социальная ориентированность & $.514(.000)$ \\
\hline Качество жизни & $.458(.000)$ \\
\hline Расходы на ИКТ & $.076(.490)$ \\
\hline
\end{tabular}

Если обратиться непосредственно к данным (рис. 1), то действительно, в развитии ЭУ и человеческого потенциала сопоставимы и регионы-лидеры, и субъекты с относительно невысокими показателями. К первым, в частности, мы можем отнести Москву, Санкт-Петербург, Ханты-Мансийский $\mathrm{AO}$, которые также относятся и к субъектам с наибольшими социальными расходами. Такие регионы, как Республика Тыва, Еврейская 
автономная область, Ивановская область, субъекты Северо-Кавказского федерального округа, в целом демонстрируют средние или низкие показатели по обоим индексам. При этом есть и случаи, которые выбиваются из подобной линейной взаимосвязи: существуют регионы с высоким уровнем человеческого развития, но низким уровнем развития каналов ЭУ (например, Тюменская область, Ямало-Ненецкий АО), а также субъекты, демонстрирующие обратную динамику (например, Псковская и Курганская области).

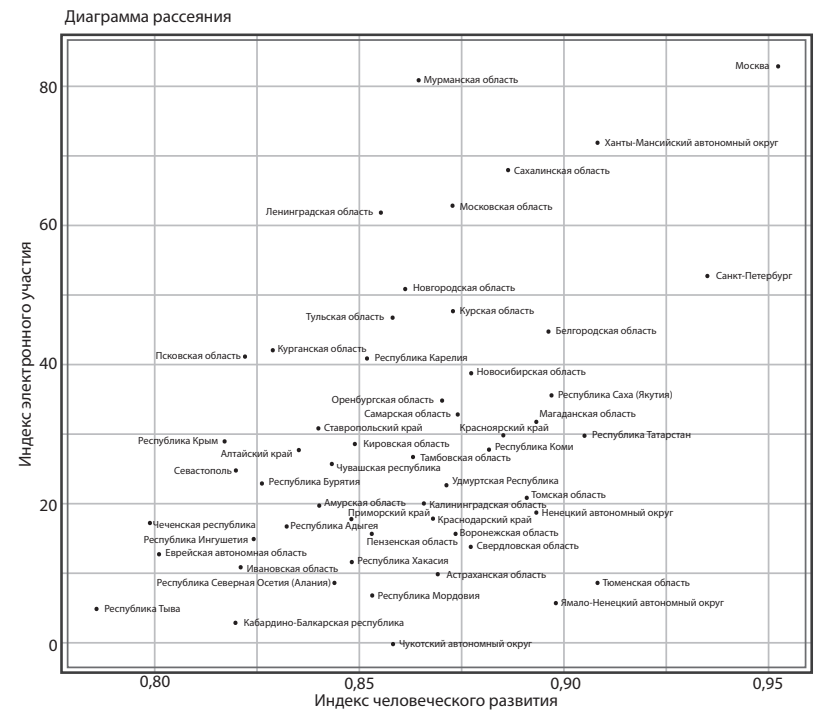

Рисунок 1. Диаграмма рассеяния индекса человеческого развития и индекса развития электронного участия в регионах России

Результаты регрессионного анализа (табл. 2) демонстрируют, что человеческий потенциал является значимым фактором развития ЭУ по сравнению с другими переменными. Значимость теряется лишь при включении показателя социальной ориентированности, которая в итоге и является наиболее важным предиктором в моделях. Однако следует помнить, что социальная политика и человеческое развитие сильно взаимосвязаны между собой: и на уровне теории, и на уровне эмпирического анализа (коэффициент корреляции - .540). Интерактивная переменная (произведение ИЧР 2016 г. и рейтинга социальной ориентированности) также показывает свою значимость в модели.

Безусловно, полученные результаты нуждаются в уточнении, а низкий коэффициент детерминации подсказывает наличие других факторов, влияющих на развитие ЭУ. Однако мы можем сделать вывод о том, что первая и вторая гипотеза нашего исследования являются правдоподобными. 
Развитие ЭУ в российских регионах действительно значимо и положительно связано как с уровнем человеческого потенциала, так и с ростом социальной ориентированности региональной политики.

Таблица 2

Результаты регрессионного анализа (источник: расчеты авторов)

\begin{tabular}{|c|c|c|c|c|c|c|c|c|}
\hline \multirow[b]{2}{*}{ Переменные } & \multicolumn{8}{|c|}{ Стандартизированные бета-коэффициенты (значимость) } \\
\hline & 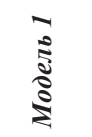 & 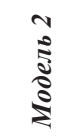 & $\begin{array}{l}n \\
\vdots \\
\vdots \\
\vdots \\
\vdots\end{array}$ & 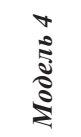 & 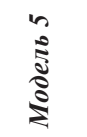 & 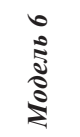 & $\frac{1}{\tilde{s}}$ & 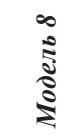 \\
\hline ИЧР & $\begin{array}{r}.404 \\
(.000)\end{array}$ & - & - & - & $\begin{array}{r}.159 \\
(.189)\end{array}$ & - & - & - \\
\hline Качество жизни & - & $\begin{array}{r}.450 \\
(.000)\end{array}$ & $\begin{array}{r}.256 \\
(.038)\end{array}$ & $\begin{array}{r}.227 \\
(.071)\end{array}$ & - & - & - & - \\
\hline $\begin{array}{l}\text { Социальная } \\
\text { ориентирован- } \\
\text { ность }\end{array}$ & - & - & $\begin{array}{r}.371 \\
(.001)\end{array}$ & $\begin{array}{r}.353 \\
(.001)\end{array}$ & $\begin{array}{r}.372 \\
(.001)\end{array}$ & $\begin{array}{r}.443 \\
(.000)\end{array}$ & - & - \\
\hline $\begin{array}{l}\text { ИЧР * Социаль- } \\
\text { ная ориентиро- } \\
\text { ванность }\end{array}$ & - & - & - & - & - & - & $\begin{array}{r}.457 \\
(.000)\end{array}$ & $\begin{array}{r}.517 \\
(.000)\end{array}$ \\
\hline $\begin{array}{l}\text { Уровень развития } \\
\text { политических } \\
\text { институтов }\end{array}$ & $\begin{array}{r}.099 \\
(.328)\end{array}$ & $\begin{array}{r}147 . \\
(.136)\end{array}$ & $\begin{array}{r}.131 \\
(.157)\end{array}$ & $\begin{array}{r}.060 \\
(.542)\end{array}$ & $\begin{array}{r}.045 \\
(.649)\end{array}$ & $\begin{array}{r}.063 \\
(.528)\end{array}$ & $\begin{array}{r}.060 \\
(.540)\end{array}$ & $\begin{array}{r}.119 \\
(.244)\end{array}$ \\
\hline $\begin{array}{l}\text { Качество государ- } \\
\text { ственного } \\
\text { управления }\end{array}$ & $\begin{array}{r}.094 \\
(.375)\end{array}$ & $\begin{array}{r}-.001 \\
(.995)\end{array}$ & $\begin{array}{r}.008 \\
(.938)\end{array}$ & $\begin{array}{r}.034 \\
(.752)\end{array}$ & $\begin{array}{r}.091 \\
(.363)\end{array}$ & $\begin{array}{r}.125 \\
(.198)\end{array}$ & $\begin{array}{r}.116 \\
(.232)\end{array}$ & $\begin{array}{r}.110 \\
(.247)\end{array}$ \\
\hline Расходы на ИКТ & - & - & - & - & - & - & - & $\begin{array}{l}-.193 \\
(.061)\end{array}$ \\
\hline СЗФО & - & - & - & $\begin{array}{r}.174 \\
(.081)\end{array}$ & $\begin{array}{r}.162 \\
(.107)\end{array}$ & $\begin{array}{r}.169 \\
(.095)\end{array}$ & $\begin{array}{l}.165 \\
(.100)\end{array}$ & $\begin{array}{r}.170 \\
(.085)\end{array}$ \\
\hline СКФО & - & - & - & $\begin{array}{l}-.086 \\
(.374)\end{array}$ & $\begin{array}{l}-.094 \\
(.340)\end{array}$ & $\begin{array}{l}-.133 \\
(.160)\end{array}$ & $\begin{array}{r}-.121 \\
(.200)\end{array}$ & $\begin{array}{l}-.126 \\
(.174)\end{array}$ \\
\hline $\begin{array}{l}\text { Скорректирован- } \\
\text { ный R-квадрат }\end{array}$ & .194 & .203 & .299 & .317 & .304 & .297 & .306 & .328 \\
\hline Ст. ошибка & 16.07 & 15.98 & 14.98 & 14.78 & 14.92 & 15 & 14.9 & 14.7 \\
\hline
\end{tabular}

\section{Заключение}

В результате проведенного анализа можно сделать вывод о том, что неоднократно отмеченный в литературе тезис о важности социального контекста в развитии ЭУ находит подтверждение и в случае российских 
регионов. Даже с учетом региональных особенностей политико-управленческих систем и расходов на информатизацию субъекты РФ с более высоким уровнем человеческого развития и социальных расходов демонстрируют более успешные практики электронного участия. Нельзя утверждать, что потенциальное «общественное давление», которое создается через человеческое развитие, с неизбежностью приводит к росту спроса на электронное участие или предложения подобных инициатив со стороны государства. Необходимы дальнейшие исследования и поиск дополнительных факторов. Однако наш анализ подчеркивает важность социальной политики для развития электронного гражданского участия. Чтобы каналы участия стали «обитаемыми», за вложениями в цифровую инфраструктуру должны следовать меры по формированию спроса на подобные механизмы, который обеспечивается активным инвестированием в человеческий потенциал.

Первое возможное направление таких инвестиций- выравнивание возможностей через повышение качества жизни незащищенных социальных групп, исключенных из процессов электронного участия. Речь идет не только о вложениях в цифровые компетенции вроде ИКТ-грамотности, но и об обеспечении достаточного уровня дохода, образования и социального благополучия. Это является условием появления у таких людей запроса на вовлечение в публичную политику и чувства значимости собственного вклада в обсуждение общественно значимых вопросов. Хотя наши данные не позволяют экстраполировать выводы на индивидуальный уровень, в региональном разрезе социальное благополучие региона действительно имеет значение для развития механизмов электронного гражданского участия.

Второе направление связано с активной социальной политикой по отношению тех, кто не относится к уязвимым группам. Для таких людей повышение запроса на участие может быть связано с личной заинтересованностью в том, какие меры государство предпринимает. Поэтому развитие социальных программ для активного населения, социальное инвестирование в образование и занятость могут стать стимулом их включения в публичную политику, что положительно скажется на востребованности ЭУ. Специальные усилия необходимо приложить к преодолению межпоколенческого разрыва в использовании электронных сервисов, поскольку объективно они больше нужны старшему поколению, а не молодежи. Предположим, например, что нуждающихся в длительном уходе пожилых нужно в первую очередь обеспечить планшетами и обучить выходу в интернет-пространство. Такие инвестиции в ИКТ-грамотность населения будут способствовать превращению экосистемы электронного участия в «обитаемые» пространства диалога власти и общества. В свою очередь, действенные механизмы электронного участия позволят более эффективно проводить социальную политику на основе учета мнений и потребностей граждан.

Третье направление- выравнивание региональных диспропорций, которые в случае российского ЭУ особенно заметны. Здесь следует отметить как меры 
по повышению качества жизни в регионах с относительно низким уровнем развития человеческого потенциала, так и выравнивание качества жизни в отдельных субъектах. Регионам необходимо не только поддерживать спрос на ЭУ (где человеческое развитие ниже уровня развития ЭУ), но и отвечать на него, предоставляя возможность качественных электронных сервисов.

Наконец, социальные инвестиции в цифровизацию публичной политики не должны ограничиваться вложениями в ИКТ-инфраструктуру и государственные информационные ресурсы. Поддержка цифровых компетенций граждан, общественных инициатив в области онлайн-участия и усиление роли местных сообществ- все это также является формой инвестирования, при которой социальная политика будет трансформироваться в лучшую сторону благодаря эффективной «обратной связи» с населением. Таким образом, развитие экосистемы ЭУ региона становится важным фактором усиления роли гражданского общества в социально-экономической политике регионов.

\section{Выражение признательности}

В статье использованы результаты проекта «Электронное участие как фактор динамики политического процесса и процесса принятия государственных решений», выполняемого при поддержке Российского научного фонда (№ 18-18-00360).

\section{Список источников}

CNews Analytics (2019) Рейтинг ИКТ-бюджетов регионов 2019. Доступно по ссылке: https:// www.cnews.ru/reviews/ikt_v_gossektore_2019/review_table/c99d29f1dd75918cbd1626d516558d a453fa6le8 (дата обращения: 18 октября 2020).

Волошинская А. А. (2016) «Электронное участие» в России: новый инструмент взаимодействия государства и общества или электронная потемкинская деревня? Информаиионное общество, (1): 40-47.

Голяшев А. В., Лобанов А. А. (2018) Индекс человеческого развития: международные и региональные различия. С.Н. Бобылев, Л. М. Григорьев (ред.) Человек и инновации. Доклад о человеческом развитии в Российской Федераџии за 2018 год. М.: Аналитический центр при Правительстве Российской Федерации: 156-169.

Кынев А.В. (2017) Качество региональных политических институтов: попытка измерения. Политическая наука, (4): 259-283.

Орлов Д., Туровский Р. (2020) VII Рейтинг эффективности управления в субъектах Российской Федерации в 2019 году. Агентство политических и экономических коммуникачий. Доступно по ссылке: http://www.apecom.ru/projects/item.php? SECTION_ID=90\&ELEMENT_ID=5869 (дата обращения: 18 октября 2020).

Ревякин С.А. (2018) Об эффективности электронных платформ участия граждан в государственном управлении. Bопросы государственного и муниципального управления, (2): 94-113.

РИА Рейтинг (2020а) Качество жизни в российских регионах-рейтинг 2019. Доступно по ссылке: https://riarating.ru/infografika/20200217/630153946.html (дата обращения: 18 октября 2020).

РИА Рейтинг (2020b) Рейтинг регионов по социальной ориентированности бюджетов в 2019 году. Доступно по ссылке: https://riarating.ru/infografika/20200526/630170121.html (дата обращения: 18 октября 2020). 
Чугунов А.В. (2017) Взаимодействие граждан с властью как канал обратной связи в институциональной среде электронного участия. Власть, 25 (10): 59-66.

Чугунов А.В., Филатова О.Г. (ред.) (2020) Электронное участие: конщептуализация и практика реализаиии в России. СПб., Изд-во «Алетейя».

Chugunov A. V., Kabanov Y., Zenchenkova K. (2016) Russian e-Petitions Portal: Exploring Regional Variance in Use. $8^{\text {th }}$ International Conference on Electronic Participation (ePart). Guimarães: HAL: 109-122.

Chugunov A., Kabanov Y., Panfilov G. (2020) Regional E-participation Portals Evaluation: Preliminary Results from Russia. Proceedings of Ongoing Research, Practitioners, Workshops, Posters, and Projects. Linköping: EGOV-CeDEM-ePart 2020:71-78.

Gel'man V., Starodubtsev A. (2016) Opportunities and Constraints of Authoritarian Modernisation: Russian Policy Reforms in the 2000s. Europe-Asia Studies, 68 (1):97-117.

Hargittai E., Jennrich, K. (2016) The online participation divide. In: M. Lloyd, L. A. Friedland (eds.) The communication crisis in America, and how to fix it. New York: Palgrave Macmillan: 199-213.

Hemerijck A. (2018) Social Investment as a Policy Paradigm. Journal of European Public Policy, 25 (6): 810-827.

Jho W., Song K. J. (2015) Institutional and Technological Determinants of Civil E-participation: Solo or Duet? Government Information Quarterly, 32 (4): 488-495.

Jenson J. (2012) Redesigning Citizenship Regimes after Neoliberalism: Moving towards Social Investment. In: N. Morel, B. Palier, J. Palme (eds.) Towards a Social Investment Welfare State? Ideas, Policies and Challenges. Bristol: Policy Press: 61-87.

Kabanov Y., Sungurov A. (2016) E-Government Development Factors: Evidence from the Russian Regions. In: A. Chugunov, R. Bolgov, Y. Kabanov, G. Kampis, M. Wimmer (eds.) Digital Transformation and Global Society. Cham: Springer: 85-95.

Kabanov Y., Chugunov A.V. (2017) Electronic 'Pockets of Effectiveness': E-governance and Institutional Change in St. Petersburg, Russia. Electronic Government. EGOV 2017. Lecture Notes in Computer Science. St. Petersburg:386-398.

Krishnan S., Teo T. S., Lymm J. (2017) Determinants of Electronic Participation and Electronic Government Maturity: Insights from Cross-Country Data. International Journal of Information Management, 37 (4): 297-312.

Lee C.P., Chang K., Berry F. S. (2011) Testing the Development and Diffusion of E-government and E-Democracy: A Global Perspective. Public Administration Review, 71 (3): 444-454.

Marx P., Nguyen C. G. (2018) Political Participation in European Welfare States: Does Social Investment Matter? Journal of European Public Policy, 25 (6): 912-943.

Misuraca G., Pasi G, Urzi Brancati C. (2017) ICT-Enabled Social Innovation: Evidence \& Prospective. Luxembourg: Publications Office of the European Union.

Norris P. (2001) Digital Divide: Civic Engagement, Information Poverty, and the Internet Worldwide. Cambridge: Cambridge University Press.

Pirannejad A., Janssen M., Rezaei J. (2019) Towards a Balanced E-participation Index: Integrating Government and Society Perspectives. Government Information Quarterly, 36 (4): 101404.

Spirakis G., Spiraki C., Nikolopoulos K. (2010) The Impact of Electronic Government on Democracy: E-democracy through E-participation. Electronic Government, an International Journal, 7 (1): 75-88.

Shore J. (2020) How social policy impacts inequalities in political efficacy. Sociology Compass, 14(5): e12784.

Tavares A.F., Martins J., Lameiras M. (2020) Electronic Participation in a Comparative Perspective: Institutional Determinants of Performance. In: M.P. Rodríguez Bolívar, M.E. Cortés Cediel (eds.) Digital Government and Achieving E-Public Participation: Emerging Research and Opportunities. Hershey: IGI Global: 87-123. 
Yury Kabanov, Andrei Chugunov

\title{
HUMAN DEVELOPMENT, SOCIAL POLICY AND CITIZEN ELECTRONIC PARTICIPATION IN RUSSIA'S REGIONS
}

\begin{abstract}
Human development, social policy and e-participation are interdependent. Effective social investment in the human capital leads to the emergence of demand for participation mechanisms among citizens, which in turn results in the willingness of authorities to implement participatory innovations. At the same time, e-participation is itself a part of the social investment paradigm, aimed at raising the quality of citizen feedback on social and economic policy. This paper attempts to test this interrelationship in the case of the Russian regions. Recently regional authorities have introduced a lot of e-participation platforms. However, many researchers emphasize the insufficient effectiveness of such platforms, as well as disproportions in their development at the regional level. Using an original evaluation methodology, we have estimated the quality of the regional e-participation portals. These data have been used in a quantitative study. The results of correlation and regression analysis suggest that human development and social expenses of the regions are important factors of e-participation development, in comparison to other potential predictors, like quality of political institutions, quality of governance and IT-expenses. It is impossible to say that human development inevitably leads to the growth of demand on e-participation among citizens, or the supply of such services from the government. However, the analysis shows that social policy is important for e-participation development: despite investment in ICT, regional authorities should actively contribute to social investment. Possible directions of such investment include providing equal opportunities via raising the living standards of the unprotected social groups, developing social programs for active citizens, eliminating regional disparities, as well as investing in the digital capabilities of citizens and civic initiatives.
\end{abstract}

Keywords: human development, social investment, e-participation, civil society, Russian regions

DOI: 10.17323/727-0634-2021-19-1-101-114

\section{References}

Chugunov A. V. (2017) Vzaimodejstvie grazhdan s vlast'yu kak kanal obratnoj svyazi v institucional'noj srede elektronnogo uchastiya [Cooperation of Citizens with the Authority as a Feedback Channel in E-participation: Institutionalization Issues]. Vlast' [Power], 25 (10): 59-66.

Yury Kabanov - senior lecturer, Department of Political Science and International Relations, research fellow, Centre for Comparative Governance Studies, National Research University 'Higher School of Economics'; analyst, E-Government Center, Institute of Design \& Urban Studies, ITMO University, St. Petersburg, Russian Federation. Email: ykabanov@hse.ru

Andrei V. Chugunov- Cand. Sci. (Polit.), Director, E-Governance Center, Institute of Design \& Urban Studies, ITMO University, St. Petersburg, Russian Federation. Email: chugunov@itmo.ru 
Chugunov A.V., Filatova O.G., eds. (2020) Elektronnoe uchastie: kontseptualizatsiya i praktika realizatsii $v$ Rossii [Electronic Participation: Conceptualization and Implementation Practice in Russia]. SPb., Izd-vo 'Aletejja'.

Chugunov A. V., Kabanov Y., Zenchenkova K. (2016) Russian e-Petitions Portal: Exploring Regional Variance in Use. $8^{\text {th }}$ International Conference on Electronic Participation (ePart). Guimarães: HAL: 109-122.

Chugunov A., Kabanov Y., Panfilov G. (2020) Regional E-participation Portals Evaluation: Preliminary Results from Russia. Proceedings of Ongoing Research, Practitioners, Workshops, Posters, and Projects. Linköping: EGOV-CeDEM-ePart 2020: 71-78.

CNews Analytics (2019) Rejting IKT-byudzhetov regionov 2019 [Rating of ICT-budgets of the regions 2019]. Available at: https://www.cnews.ru/reviews/ikt_v_gossektore_2019/review_table/c99d29f1dd75918cbd1626d516558da453fa61e8 (accessed: 18 October 2020).

Gel'man V., Starodubtsev A. (2016) Opportunities and Constraints of Authoritarian Modernisation: Russian Policy Reforms in the 2000s. Europe-Asia Studies, 68 (1): 97-117.

Golyashev A. V., Lobanov A.A. (2018) Indeks chelovecheskogo razvitiya: mezhdunarodnye i regional'nye razlichiya [Human Development Index: International and Regional Differences]. In: S.N. Bobylev, L. M. Grigor'ev (eds.) Chelovek i innovacii. Doklad o chelovecheskom razvitii v Rossijskoj Federacii za 2018 god [Human and Innovations. Report on Human Development in the Russian Federation in 2018]. Moscow: Analiticheskij centr pri Pravitel'stve Rossijskoj Federacii: 156-169.

Hargittai E., Jennrich, K. (2016) The Online Participation Divide. In: M. Lloyd, L. A. Friedland (eds.) The Communication Crisis in America, and How to Fix It. New York: Palgrave Macmillan: 199-213.

Hemerijck A. (2018) Social Investment as a Policy Paradigm. Journal of European Public Policy, 25 (6): 810-827.

Jho W., Song K. J. (2015) Institutional and Technological Determinants of Civil E-participation: Solo or Duet? Government Information Quarterly, 32 (4): 488-495.

Jenson J. (2012) Redesigning Citizenship Regimes after Neoliberalism: Moving towards Social Investment. In: N. Morel, B. Palier, J. Palme (eds.) Towards a Social Investment Welfare State? Ideas, Policies and Challenges. Bristol: Policy Press: 61-87.

Kabanov Y., Sungurov A. (2016) E-Government Development Factors: Evidence from the Russian Regions. In: A. Chugunov, R. Bolgov, Y. Kabanov, G. Kampis, M. Wimmer (eds.) Digital Transformation and Global Society. Cham: Springer: 85-95.

Kabanov Y., Chugunov A. V. (2017) Electronic 'Pockets of Effectiveness': E-governance and Institutional Change in St. Petersburg, Russia. Electronic Government. EGOV 2017. Lecture Notes in Computer Science. St. Petersburg:386-398.

Krishnan S., Teo T. S., Lymm J. (2017) Determinants of Electronic Participation and Electronic Government Maturity: Insights from Cross-Country Data. International Journal of Information Management, 37 (4): 297-312.

Kynev A. V. (2017) Kachestvo regional'nykh politicheskikh institutov: popytka izmereniya [Quality of Regional Political Institutions: Attempt of Measurement]. Politicheskaya nauka [Political Science], (4): 259-283. 
Lee C.P., Chang K., Berry F. S. (2011) Testing the Development and Diffusion of E-government and E-Democracy: A Global Perspective. Public Administration Review, 71 (3):444-454.

Marx P., Nguyen C. G. (2018) Political Participation in European Welfare States: Does Social Investment Matter? Journal of European Public Policy, 25 (6): 912-943.

Misuraca G., Pasi G, Urzi Brancati C. (2017) ICT-Enabled Social Innovation: Evidence \& Prospective. Luxembourg: Publications Office of the European Union.

Norris P. (2001) Digital Divide: Civic Engagement, Information Poverty, and the Internet Worldwide. Cambridge: Cambridge University Press.

Orlov D., Turovskij R. (2020) VII Rejting effektivnosti upravleniya v sub"ektah Rossijskoj Federacii v 2019 godu [VII Rating of Effectiveness of Governance in the Regions of the Russian Federation in 2019]. Agentstvo politicheskih $i$ ekonomicheskih kommunikacij [Agency of Political and Economic Communications]. Available at: http://www.apecom.ru/projects/ item.php? SECTION_ID=90\&ELEMENT_ID=5869_accessed 18 October 2020).

Pirannejad A., Janssen M., Rezaei J. (2019) Towards a Balanced E-participation Index: Integrating Government and Society Perspectives. Government Information Quarterly, 36 (4): 101404.

RIA Rating (2020a) Kachestvo zhizni v rossijskih regionah-rejting 2019 [Quality of Life in the Russian Regions - Rating 2019]. Available at: https://riarating.ru/infografika/2020 0217/630153946.html (accessed: 18 October 2020).

RIA Rating (2020b) Rejting regionov po social'noj orientirovannosti byudzhetov v 2019 godu [Rating of Regions According to the Social Orientation of their Budgets in 2019]. Available at: https://riarating.ru/infografika/20200526/630170121.html (accessed: 18 October 2020).

Revyakin S.A. (2018) Ob effektivnosti elektronnyh platform uchastiya grazhdan v gosudarstvennom upravlenii [On the Effectiveness of Citizen Electronic Participation Platforms in Public Administration]. Voprosy gosudarstvennogo i municipal'nogo upravleniya [Public Administration Issues], (2): 94-113.

Spirakis G., Spiraki C., Nikolopoulos K. (2010) The Impact of Electronic Government on Democracy: E-democracy through E-participation. Electronic Government, an International Journal, 7 (1): 75-88.

Shore J. (2020) How Social Policy Impacts Inequalities in Political Efficacy. Sociology Compass, 14 (5): e12784.

Tavares A. F., Martins J., Lameiras M. (2020) Electronic Participation in a Comparative Perspective: Institutional Determinants of Performance. In: M.P. Rodríguez Bolívar, M. E. Cortés Cediel (eds.) Digital Government and Achieving E-Public Participation: Emerging Research and Opportunities. Hershey: IGI Global: 87-123.

Voloshinskaya A.A. (2016) 'Elektronnoe uchastie' v Rossii: novyj instrument vzaimodejstviya gosudarstva i obshchestva ili elektronnaya potemkinskaya derevnya? ['Electronic Participation in Russia': A New Instrument of Interaction between State and Society or a Potemkin E-village?]. Informacionnoe obshchestvo [Information Society], (1):40-47. 